Database Structure for a Multi Stage Stochastic Optimization

Based Decision Support System for Asset - Liability Management of a Life Insurance Company

Harish V. Rao

Goutam Dutta

Sankarshan Basu

W.P. No.2014-06-02

June 2014

The main objective of the working paper series of the IIMA is to help faculty members, research staff and doctoral students to speedily share their research findings with professional colleagues and test their research findings at the pre-publication stage. IIMA is committed to maintain academic freedom. The opinion(s), view(s) and conclusion(s) expressed in the working paper are those of the authors and not that of IIMA.

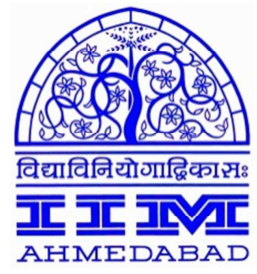

INDIAN INSTITUTE OF MANAGEMENT

AHMEDABAD-380 015

INDIA 


\title{
Database Structure for a Multi Stage Stochastic Optimization Based Decision Support System for Asset - Liability Management of a Life Insurance Company
}

\author{
Harish V. Rao \\ Jindal Global School of Business, New Delhi \\ Email: harishrao@iimahd.ernet.in \\ Goutam Dutta \\ Indian Institute of Management, Ahmedabad, 380015, India \\ Email: goutam@iimahd.ernet.in \\ Sankarshan Basu \\ Indian Institute of Management, Bangalore, India \\ Email: sankarshanb@iimb.ernet.in
}

\begin{abstract}
We introduce a stochastic optimization based decision support system (DSS) for asset-liability management of a life insurance firm using a multi-stage, stochastic optimization model. The DSS is based on a multi-stage stochastic linear program (SLP) with recourse for strategic planning. The model can be used with little or no knowledge of management sciences. The model maximizes the expected value of total reserve (policy holders' reserve and shareholders' reserve) at the end of the time period of planning. We discuss the issues related to database design structure, DSS interface design, database updating procedure, and solution reporting.
\end{abstract}

Keywords: Decision support system, stochastic optimization, financial institutions, strategic planning, asset liability management, insurance 


\section{Database Structure for a Multi Stage Stochastic Optimization Based Decision Support System for Asset - Liability Management of a Life Insurance Company}

\section{Introduction and Motivation}

Asset Liability Management (ALM), the practice of managing risks arising due to a mismatch between assets and liabilities, is one of the key aspects of risk faced by all financial institutions. The matching of assets and liabilities can be modeled by mathematical equations representing inflows and outflows. The ALM model also considers the financial flow related to the carry over of the gains (or losses) from one period to the next and the objective function of this model is to maximize the present value of the amount at the end of the planning horizon.

Dhar \& Stein [5], Holsapple \& Whinston [19], Fayyad [12], Sprague \& Watson [26,], Turban and Aronson [27] are notable amongst the numerous papers that have been published, that focus on the database design aspect of DSS and its applications in process manufacturing industries. However, literature is rather scarce when it comes to studying the development of a DSS for addressing ALM related problems. In this paper, we introduce a stochastic optimization based DSS for asset-liability management of a life insurance firm using a multi stage, multi-period stochastic optimization model.

\subsection{Context of the research}

The life insurance industry is an extremely competitive industry wherein a firm is faced with stiff competition not only from other players in the industry but also from other competing financial institutions such as banks and pension funds, for its fund inflows. Life insurance policies are no longer looked at only as risk mitigation transactions, but also as an avenue for generating investments returns. The growth of a firm, in this context, significantly relies on its ability to maximize the utility towards its 
investors by maximizing the worth of its investments. But unlike other financial institutions, life insurance firms have to deal not only with fluctuating economic conditions but also the uncertain life expectancy of its investors. Uncertainty and multi-period problems are inherent to managing financial institutions. These uncertainties compound the problem of ALM in a life insurance firm and hence, make it more challenging. In this paper, we attempt to address the following questions in detail:

1. How is the database design of SLP in ALM similar to that of SLP in process industries?

2. What are the difficulties encountered in developing a multi-stage multi-scenario DSS?

3. What are the key features of a multi-scenario multi-stage DSS?

4. What are the challenges in the implementation of the update mode in a multi-scenario multi-period DSS?

5. How the variable and constraint generation process is different from a multi stage SLP based DSS to that of a two stage SLP based DSS?

\subsection{Review of Related Research}

Stochastic programming is one of the tools available to deal with such uncertainties. In a survey of stochastic programming applications, Birge[2] claims that using stochastic programming techniques, robust "near optimal" solutions can be obtained in decisions regarding allocating resources while facing an uncertain future. Mathematical models of asset liability management have been extensively studied by academicians and practitioners; a few key studies are the ones by Markowitz [21,22], Carino et al. [3] and Kusy \& Ziemba [20]. In the SLP, the scenarios for asset returns can be generated from different sources like different interest rate models (Mulvey et al. [23]) or by the use of autoregressive modelling on past data as suggested by Carino, Myers \& Ziemba [5].

The framework provided by Dolk [6] for data, model and dialogue management is a good starting point for this study. In this paper, we draw on the findings from existing literature on structured modeling (Geoffrion $[15,16,17])$ and modeling language, mathematical programming, and database optimization 
interface literature Dutta [7], (Dutta \& Fourer [8, 9]; Fourer [13],) to develop a robust model for a DSS for the firm we are interested in. Fourer et al. [14] discusses the features of modelling languages. This study also draws ideas and concepts from a similar framework for modeling languages developed by Valante et al. [28].

While several researchers ([Carino \& Ziemba [4], Carino et al. [3]) have attempted to develop a SLP to model uncertainty in ALM and there have been some attempts to develop a DSS on process industries, this is probably the first attempt to develop a SLP based DSS for strategic planning for an insurance firm. Moreover while the earlier researchers have addressed only the asset side risks, in this work, we also model liability side risks. We believe that this research will be useful for two audiences. The first is academicians who are looking for new research areas and second, practitioners in insurance companies, who are looking for the application of such DSS.

In this paper, we introduce a stochastic optimization based DSS for an ALM problem for an insurance firm with the following features:

1. User friendliness, so that an executive with little or no mathematical background can comfortably use this DSS

2. Multi - period planning

3. Multiple scenario optimization

4. Flexibility to modify periods, scenarios, assets, and liability classes

5. Flexibility to explore "what - if" scenarios

\subsection{Outline}

Section 2 consists of the discussion on the design issues and challenges faced in designing a multiscenario, multi-period database and briefly introduce the different elements of the database as well as the complete DSS. It looks at the correspondence of the files of data management system in the DSS with the variables and constraints in the linear program. In Section 3, we discuss the steps in multi- 
scenario, multi-period optimization - constraint, variable and coefficient generation, solution of the optimization problem and reading of optimal values into the database. In Section 4, we briefly discuss the features of the DSS and its strategic relevance to the firm. Finally, Section 5 highlights the challenges foreseen in the development of the DSS module and the expected contribution of this study to the field of database optimization.

\subsection{Two-stage recourse model}

A general two-stage recourse model (Sen \& Higle [ 25]) can be formulated as an extension to the classic stochastic problem as follows.

$\mathrm{c}_{\mathrm{i}}=$ the cost vector of the ith stage

$\mathrm{A}_{1}=$ the coefficient matrix at stage 1

$\mathrm{A}_{2 \mathrm{~s}}=$ the coefficient matrix at stage 2 in different scenarios, for $\mathrm{s}=1,2,3 \quad s \in \Omega$

$\mathrm{b}_{1}=$ the right hand side of the SLP at stage 1

$\mathrm{b}_{2 \mathrm{~s}}=$ the right hand side of the SLP in different scenarios, for $\mathrm{s}=1,2,3 \quad s \in \Omega$

$\mathrm{x}_{1}=$ First stage decision variable

$\mathrm{X}_{1 \mathrm{~s} /} \mathrm{X}_{2 \mathrm{~s}}=$ First/second stage decision variables in different scenarios, for $\mathrm{s}=1,2,3$

$$
\text { Minimize } \sum_{s \in S} p_{s}\left[c_{1} x_{1 s}+c_{2} x_{2 s}\right]
$$

s.t.

$$
\begin{array}{cc}
A_{1} x_{1 s}=b_{1} & s \in \Omega \\
B_{s} x_{1 s}+A_{2 s} x_{2 s}=b_{2 s} & s \in \Omega \\
x_{1}-x_{1 s}=0 & s \in \Omega
\end{array}
$$




$$
L_{1 s}<=x_{1 s}<=U_{1 s}, \quad L_{2 s}<=x_{2 s}<=U_{2 s} \quad s \in \Omega
$$

The constraints $A_{1} x_{1 s}=b_{1}$ include the immediate constraints (first stage variables only). This is termed as the first stage of the problem. The random variables appear in the second stage wherein the random parameters $\left(c_{2}, B, A_{2}, b_{2}\right)$ are uniquely realized for each scenario s. One of the most important notions within a stochastic programming formulation is that of implementability or non-anticipativity. This means that under uncertainty, the first stage decisions are implemented before an outcome of the random variable is observed. Since this decision is made when the outcome of the random variable is still unknown, it cannot be dependent on any particular outcome of the random variable. This explicitly recognized the first stage variables as non-anticipative. The variables $\mathrm{x}_{1 \mathrm{~s}}$ are dependent on the outcome of the realization of the random variables. But the constraint $x_{1}-x_{1 s}=0$ forces all the outcomes to be the same as $\mathrm{x}_{1}$.

Thus, a linear program with uncertainties can be modeled into a stochastic linear program. This stochastic linear program can be modeled into a deterministic equivalent LP which can then be solved as a generalized LP but with the objective function changed to maximizing expected value.

\section{Database design for multi-scenario multi-period models}

In this section we discuss the first question as described in page 2 and address the similarity of this work with that of optimization based DSS in Process Industries (Dutta [7], Fourer [13], Dutta \& Fourer [9]). One of our more recent work(Gupta et al.[18] discusses SLP based DSS in process industries. In this case, the multi-scenario, multi-period model for asset-liability management in a life insurance firm has five key or fundamental elements; Times, Scenarios, Accounts, Assets and Liabilities. In our recent work (Gupta et al. [18])), we had six primary files - Times, Scenarios, Materials, Facilities, Activities and Storage Areas. The five key elements are explained as follows: 
Times are the periods of the planning horizon represented by discrete numbers $(1,2,3 \ldots)$. The length of these periods can vary. For an ALM problem, close time periods are shorter and farther periods are longer, to take care of uncertainty in the financial parameters.

Scenarios are the possible realizations of the uncertain parameters. These can also be represented by discrete numbers $(1,2,3 \ldots)$ wherein each scenario corresponds to one realization of the uncertain parameters. A set of such scenarios is collectively termed as a scenario set.

Accounts are classified into two different accounts: the policyholders' account and the shareholders' account. The two accounts are operated independently and are connected to each other via surplus and deficient variables.

Assets form the set of the investment opportunities available for the firm. Each of these asset classes provides a return to the firm dependent on the performance of the underlying asset.

Liabilities of an insurance firm are the outflows promised by the insurance firm to its customers. These include maturity outflows, death outflows, and surrender claims.

The algebraic form of the model is provided in Appendix 1.

\subsection{Database Structure of the Data Models}

The database structure mainly has two sub-databases. The files of the first sub-database are defined as the data files or files of data management system. The files of the second sub-database, which contain the information of the stochastic linear program, are called the files of model management system or model files. The complete database structure for the stochastic optimization model is shown in figure 1 . 
Figure 1: Database Structure for the Stochastic Optimization Model

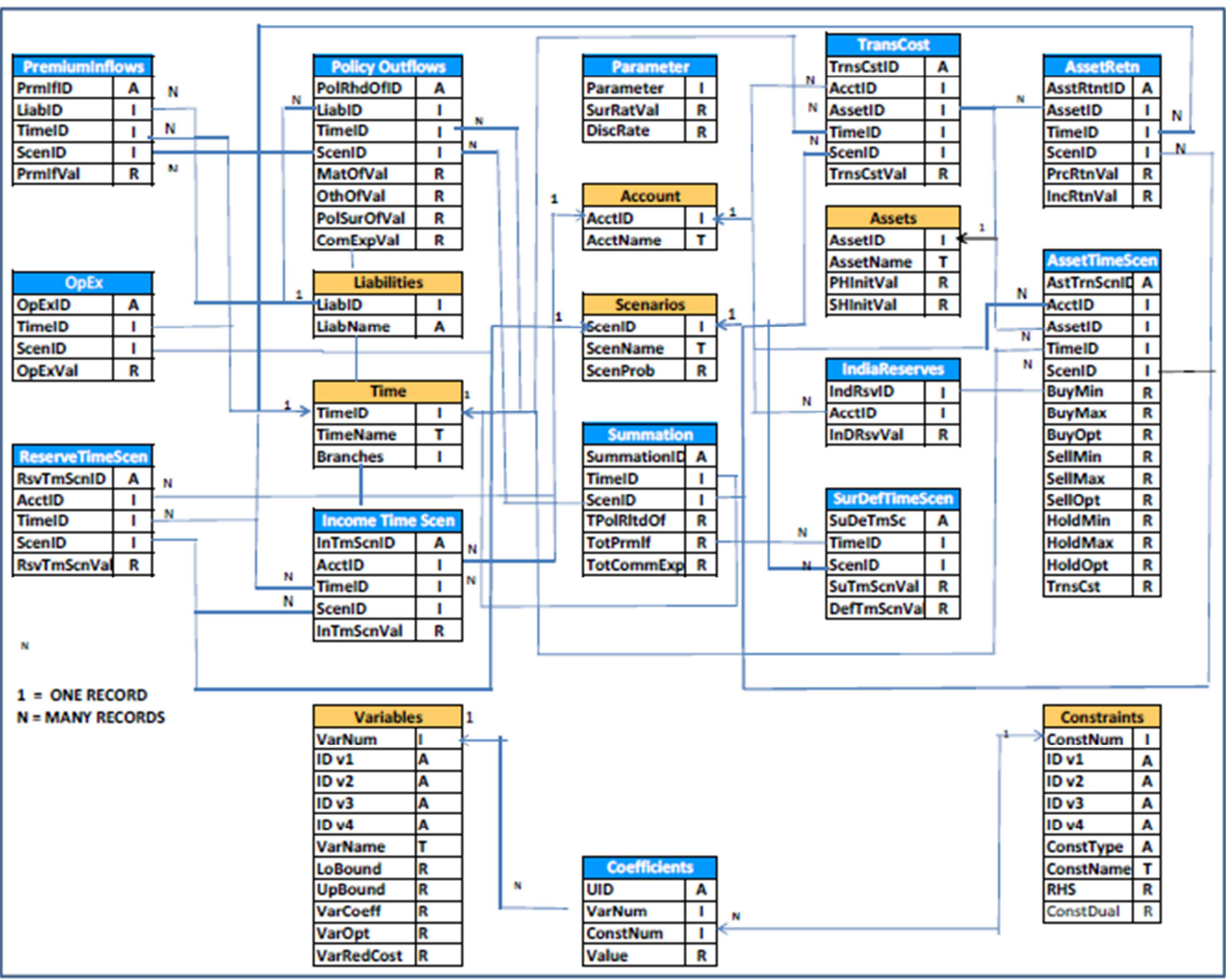

\subsection{Database Implementation of Primary Files}

We implement this database on the $4^{\text {th }}$ Dimension platform, a relational database management system developed by Adams \& Beckett [1]. First, we develop the files for the five key elements of the database. The five boxes, labeled as [Time], [Scenarios], [Assets], [Liabilities] and [Accounts] correspond to the five key elements of the database. Items within each box denote the file's data fields. 
The [Accounts] and [Liabilities] files have the data fields of only the unique ID and the name associated with them. For example, for the [Account] file, each record has the entries of the [Accounts]AcctID and [Accounts]AcctName. Similarly, for the [Liabilities] file, each record has the entries of the [Liabilities]LiabID and [Liabilities]Liabname .For the [Scenarios] file, there is [Scenarios]ScenID and [Secnarios]ScenName and an additional entry of [Scenarios]ScenProb, which contains the probability of the occurrence of the scenario. For the [Time] file, there is an additional entry of [Time] Branches, which contains the information on the scenario tree structure for the model. For the [Assets] file, there are two additional fields for the information on the initial asset allocation in the asset for the two accounts.

\subsection{Database implementation of Secondary Files}

The other files necessary for the implementation of the model are created by indexing the key elements. We shall show this by explaining two key files in the database [AssetTimeScen] file or Asset-TimeScenario file and the [PolicyOutflows] file or Ploicy Outflow file .

The [AssetTimeScen] provides the basic structure needed to define the key decision variables. As the variables are defined over the subscripts of asset class, time period, scenario and account type, the AssetTimeScen files are indexed over the following four variables: [AssetTimeScen]TimeID, [AssetTimeScen]ScenID, [AssetTimeScen]AssetID and [AssetTimeScen]AcctID. Thus, the primary key is a composite of [AssetTimeScen]TimeID, [AssetTimeScen]ScenID, [AssetTimeScen]AssetID, and [AssetTimeScen]AcctID. 
Figure 2: Linkages of Asset Time scenario Sub File

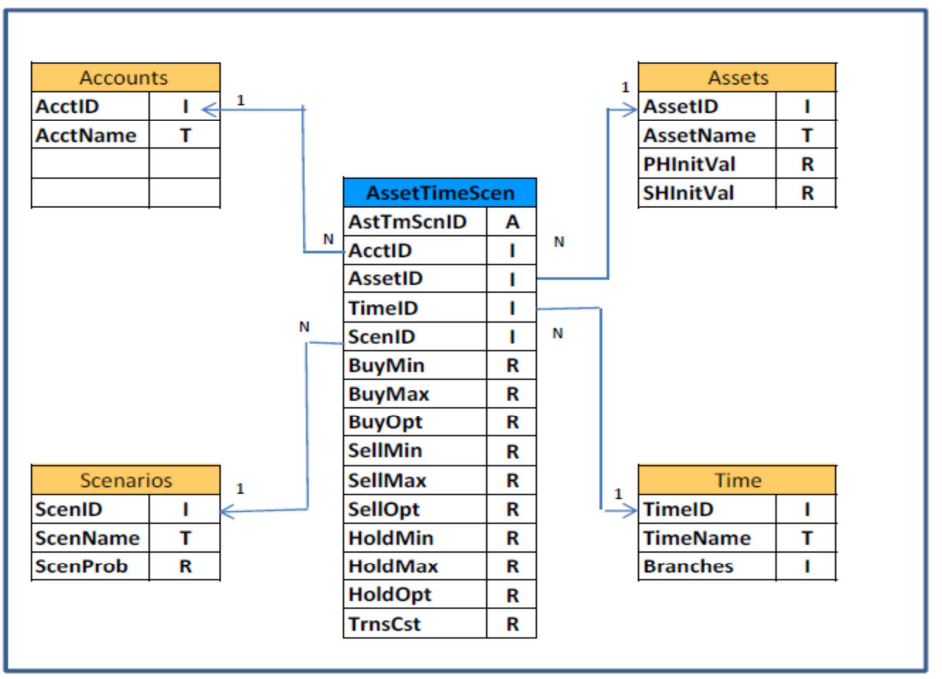

In Table 1, we show the one-to-one correspondence of fields of the [AssetTimeScen] file and the optimization model described in Appendix 1

\section{Table 1: One-to-one correspondence of variables in [AssetTimeScen] file}

\begin{tabular}{|l|c|l|}
\hline S. No. & Variables of SLP & Fields of database files \\
\hline 1 & $\mathrm{X}_{\mathrm{Mtis}}$ & [AssetTimeScen]HoldOpt \\
\hline 2 & $\mathrm{X}_{\mathrm{Mtis}}^{\text {buy }}$ & [AssetTimeScen]BuyOpt \\
\hline 3 & $\mathrm{X}_{\mathrm{Mtis}}^{\text {sell }}$ & [AssetTimeScen]SellOpt \\
\hline
\end{tabular}

Further, the following fields [AssetTimeScen]HoldMin, [AssetTimeScen]HoldMax, [AssetTimeScen]BuyMin, [AssetTimeScen]BuyMax, [AssetTimeScen]SellMin, [AssetTimeScen]SellMax, and [AssetTimeScen]TrnsCst are time, scenario, asset, and account dependent; they are modifiable either through the input layouts in the database or by importing data from an external text file; both are permitted by the DSS. The optimal values of the model are stored in the fields [AssetTimeScen]HoldOpt, [AssetTimeScen]BuyOpt and [AssetTimeScen]SellOpt of the 
[AssetTimeScen] file. These values are loaded from the solver output after receiving the optimal values from the optimizer.

In Table 2, we show the one-to-one correspondence of fields of the [AssetTimeScen] file and parameters of the optimization model. Further, Table 3 shows the one-to-one correspondence of fields of the [PolicyOutflows] file and parameters of the optimization model.

Table 2: One-to-one correspondence of parameters of SLP and Asset Time Secnario files

\begin{tabular}{|l|c|l|}
\hline S. & Parameter of SLP & Fields of database \\
\hline 1 & $\mathrm{~L}_{\text {Mtis }}$ & {$[$ AstTmScn ]HoldMin } \\
\hline 2 & $\mathrm{U}_{\text {Mtis }}$ & {$[$ AstTmScn] Holdmax } \\
\hline 3 & $\mathrm{~L}_{\text {Mtis }}^{\text {buy }}$ & [ AstTmScn ]BuyMin \\
\hline 4 & $\mathrm{U}_{\text {Mtis }}^{\text {buy }}$ & [ AstTmScn ]BuyMax \\
\hline 5 & $\mathrm{~L}_{\text {Mtis }}^{\text {sell }}$ & [ AstTmScn ]SellMin \\
\hline 6 & $\mathrm{U}_{\text {Mtis }}^{\text {sell }}$ & [ AstTmScn ]SellMax \\
\hline 7 & $\gamma_{\text {tis }}$ & [ AstTmScn ]TrnsCst \\
\hline
\end{tabular}

Table 3 : One to One correspondences of parameters of SLP and Policy Outflow file of Database

\begin{tabular}{|c|c|l|}
\hline S. No. & $\begin{array}{c}\text { Parameter } \\
\text { of SLP }\end{array}$ & \multicolumn{1}{|c|}{ Fields of database files } \\
\hline 1 & $\mathrm{~L}_{\mathrm{t} j \mathrm{~s}}$ & [PolicyOutflows]MatOfVal \\
\hline 2 & $\mathrm{Q}_{\mathrm{t} j \mathrm{~s}}$ & [PolicyOutflows]DthOfVal \\
\hline 3 & $\mathrm{E}_{\mathrm{t} \mathrm{j} s}$ & [PolicyOutflows]SurOfVal \\
\hline 4 & $\mathrm{CC}_{\mathrm{t} j \mathrm{~s}}$ & [PolicyOutflows]ComExpVal \\
\hline
\end{tabular}

\subsection{Scenarios and Time Related files}

The set, Scenarios, is the core of any stochastic model. It is linked to the primary file [Scenarios], and relational files [AssetTimeScen], [AssetRetn] representing Asset Return, [ReserveTimeScen] representing Reserve Time Scenario, [IncomeTimeScen] representing Income Time Scenario, 
[SurDefTimeScen] representing Surplus Deficit Time Scenario. Similarly, it is also linked to [PolicyOutflows] representing Policy Outflow, [PremiumInflows] representing Premium Outflow, $[\mathrm{OpEx}]$ representing Operating Expenses, [TransCost] representing transaction cost. These files contain scenario dependent information about the respective parameters and variables. The set, [Time] links along with set [Scenarios] capture the time-scenario dependent information of the various parameters. The simple structure of the [Scenarios] files is shown in figure 3.

\section{Figure 3 Structure of Scenarios File}

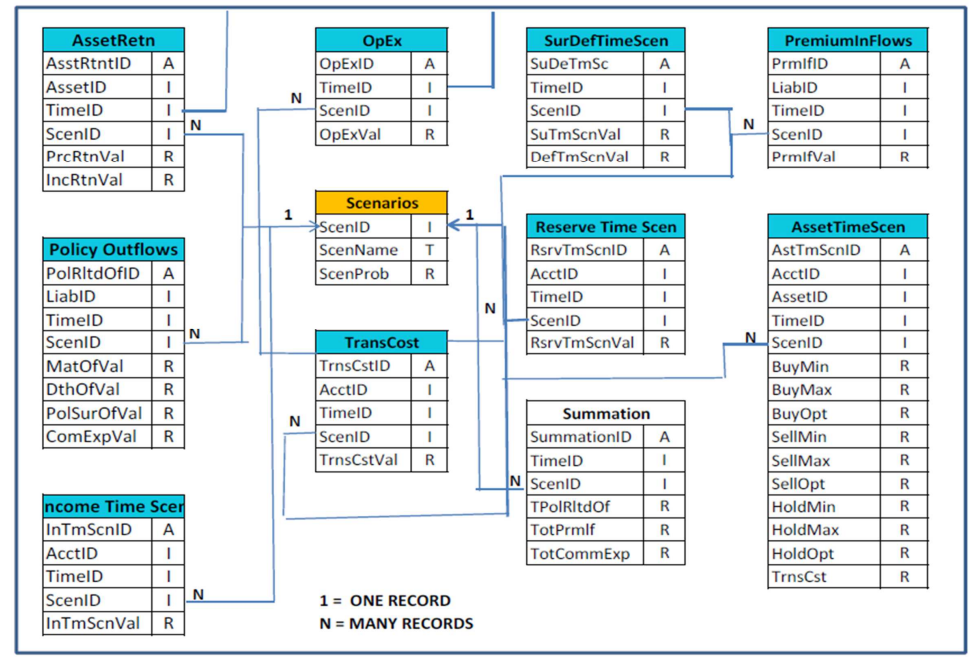

\subsection{Model Files}

As stated above, Model Files is an alternative database form of an LP representation (figure 4). This contains three files, namely [Variables], [Constraints], and [Coefficients]. The variables file contains the model parameters - upper bound, lower bound, and the objective function coefficient of each decision variable. The file [Constraints] lists the constraints and the parameters associated with each constraint, namely the right hand side of each constraint. This is the file which receives the dual values associated with each constraint. The [Coefficients] file maintains all the pairs of constraints and variables which is analogous to the technological coefficient in process industries which is non-zero. 
Figure 4 Model File

\begin{tabular}{|l|l|l|}
\hline \multicolumn{2}{|c|}{ Variables } \\
\hline VarNumber & L L ONE \\
\hline ID1 & A \\
\hline ID2 & $\mathrm{A}$ \\
\hline ID3 & $\mathrm{A}$ \\
\hline ID4 & $\mathrm{A}$ \\
\hline Type & $\mathrm{T}$ \\
\hline LoBound & $\mathrm{R}$ \\
\hline UpBound & $\mathrm{R}$ \\
\hline ObjCoeff & $\mathrm{R}$ \\
\hline VarOPT & $\mathrm{R}$ \\
\hline VarReducedCost & $\mathrm{R}$ \\
\hline
\end{tabular}

\section{Optimization}

In this section, we discuss the difficulties in a multi-stage DSS over a two stage DSS [Gupta et al. [18]) and answer the second question that we have asked on page 2 . We also partially answer the fifth question on page 2. As we know, the uncertainties present in the ALM problem are dealt with, with the help of scenarios. These scenarios are generated with the help of a scenario generator. The scenario structure over this five period horizon is chosen as $12-8-4-2-1$ and it creates 768 scenarios. This indicates that 12 scenarios will be generated over the immediate (first) period, 8 scenarios in the second period over each preceding scenario of the first period and so on. This data model is developed using Microsoft Excel. The model generates scenarios over the period length and also generates the data sets to be input to the database management module of the DSS. We can enter data manually or through a scenario generator. As the manual process is tedious, we can enter data that follows a particular statistical distribution and import the data without any manual intervention. Gupta et al. [18] discussed the SLP based DSS, but in that case, the model was only two stage and the probabilities of the second stage were entered manually. In this case since the no of possibilities are very large, manual entry is not feasible. Hence the concept of a scenario generator automatically enters the data related to parameters of SLP that follows a particular distribution. The steps of optimization are as follows and shown in Figure 5, which describes the optimization steps. 
Table 4: Description of Periods

\begin{tabular}{|c|c|c|c|}
\hline $\mathrm{t}$ & Name & Quarters & Description \\
\hline 0 & Initialization & - & Initialization \\
\hline 1 & Q01 & 1 & Quarter 1 end \\
\hline 2 & Y01 & 3 & Year 1 end \\
\hline 3 & Y02 & 4 & Year 2 end \\
\hline 4 & Y03 & 4 & Year 3 end \\
\hline 5 & Y05 & 8 & Year 5 end \\
\hline
\end{tabular}

Figure 5 : Optimization Steps

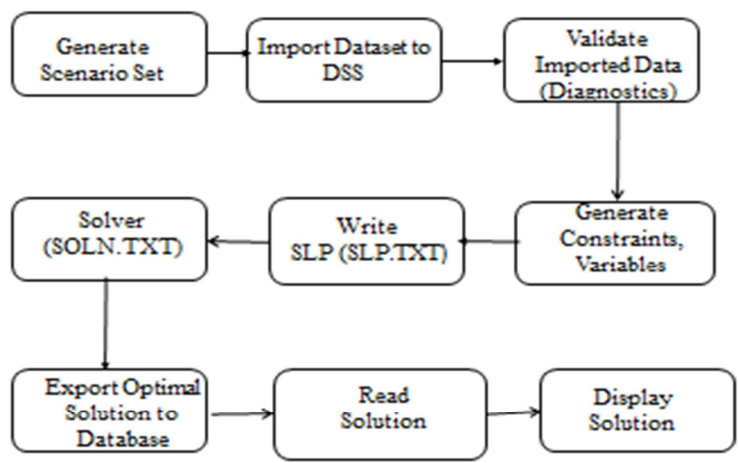

a) The scenario generator module develops the scenario sets and loads the data required for the data files of the DSS. The generated scenario set is imported into the database management module

b) The database management system then checks the database for data inconsistency errors and prompts them to the user, if any. In this case we use the diagnostics to check that the data is suitable for running a SLP. 
c) The module then generates the linear programming problem through the matrix generator code. It goes through four steps, the Constraints Generation Process and the Variables Generations. The data for the [Constraints], [Variables] and [Coefficients] file are loaded.

d) The information about the SLP generated is written into an ordinary text file to be input to the optimizer. We use the industry standard MPS version for this model (SLP.TXT).

e) This LP problem (SLP.TXT) is input to the CPLEX solver. On the user prompt, the solver takes the MPS version of the problem and returns a matrix version of the solution (SOLN.TXT)

f) The optimal solution generated by the optimizer is imported into the database in their respective fields. These are explained in Figure 5.

g) The module then runs the output format requests and outputs the optimal decisions to the user along with critical information related to the model like VaR (Value-at-Risk) or conditional Value at Risk (CVaR).

\section{Features of the DSS}

In this section we discuss the answer to the third question on page 2 . The primary objective of this study is to establish a database optimization interface which is user-friendly, generic and flexible. Further, the DSS should also be robust and least susceptible to failures. While the features may appear to be somewhat simiar to Dutta et. al. [11], we must understand that our application domain is entirely different. Here, we are an application in Financial Enginnering. The next few sub-sections describe how this has been achieved in the DSS proposed in this paper.

\subsection{User-friendliness}

In this research, we develop a user-friendly DSS which can be used regularly by a manager with a minimal advanced knowledge of MS/OR. The DSS operates in three modes: Data, Update and Optimal. The Data mode is required for data entry, and the Optimal mode displays the optimal values of the decision variable in addition to the upper and lower bounds on the variables. The Update mode 
is required to automatically make changes in the Model files corresponding to small (one or two) changes in the Data files. Switching between these modes is simple and is completely menu driven. Generating the LP representation, optimal solution updating and solution reporting can be done very easily through the menus. First, it enhances the userfriendliness of the DSS in many ways. This can be incorporated by having input layout interfaces so that reentry of data is not required. Every input layout has a drop-down list to facilitate choice of the primary data. Second, if the data can be entered from a spreadsheet, there are less chances of manual error. The third advantage is that the reduced costs and constraint duals that are important are reported in the optimal layouts. In addition to these features, we can avail of the advantages of several features like included layouts to create a custom designed layout as desired by the user.

\subsection{Generality and Flexibility}

The DSS is flexible so that can be used by any other insurance firm by substution of parameter values. The model management system and steps of optimization remain unchanged. The DSS should be flexible and generic in nature so that it evolves with changes in the model and the fundamental elements of the model. . For example, the addition of another asset class in the [Assets] file is accomplished through an added record in the [Assets] file and corresponding addition records in the data files related to the [Assets] file. Similarly, any changes in the [Liabilities] file, [Scenarios file], are easily managed. The scenario structure as defined in the [Time] file can also be modified.

The stochastic model adapts itself to any such changes in the primary files and generates the correct linear programming model. The critical part of generating non-anticipativity constraints can completely adapt itself to the data in the data files and is free from any need of user interference. In case the linear program itself needs to be changed, then a modeler needs to incorporate the changes in the formulation and varibale generation and constraint generation process, and this can be done very easily.

\subsection{Diagnostics to ensure robustness}

Implementation of diagnostic rules eliminates many common errors during data entry and updation. These rules are as follows. 
Rule 1: The probability attached to each scenario in an SLP should be non-negative and less than or equal to one.

Rule 2: The sum of probabilities associated with all the scenarios in an SLP should be exactly equal to one.

Rule 3: The user is restricted from typing the names of the instances of the primary elements in the secondary data files. The choice is restricted to the dropdown list populated by the records in the primary files

Rule 4: The number of records in a time and scenario dependent file should be less than or equal to the Cartesian product of the number of records in the [Times], [Scenarios], and other files which are linked in a one-to-many relationship. For example, in [AsstRtn] file, the number of records should not exceed the product of the records in the [Assets], [Time] and [Scenarios] files. This is accomplished by having a unique key of a secondary data file as a unique composite of the unique keys of several primary files.

Rule 5: The optimal values of decision variables from the optimizer should not differ in numerical values for the first time period. These are the first stage implementable decisions. For a tree-type scenario structure, the same holds true for every child scenario set from a common parent scenario. The non-anticipativity constraints implemented in the SLP through the matrix generator code ensure that this holds true. This provides a major challenge in the matrix generation code.

Rule 6: Unless it is specified otherwise, the lower and upper limit of a variable are set at default values (at zero and infinity respectively).

Rule 7: The constraints, variables and coefficients files form the backbone of the stochastic linear program, and these records are created by the matrix generator code which retrieves data from the data files. Thus, manual editing and changing of the records in the model files are disabled completely. 
Rule 8: Any change in the linear program has to be through the data files only. This is because the information in the model files is generated by the matrix generator code from the information in the data files. An independent editing or updating of any record in the model files may possibly cause a violation of the integrity of the stochastic model. A single parameter in the data files could be used for more than one data point in the model files. So, any updating of the record in the model files should ideally reflect in all such locations in the model files. Since this cannot be achieved by any diagnostic rule on the model files, we implement the rule that any updation of the model files must be through the updating of the data files. The Update module would then be able to reflect all the necessary changes in the model files.

\subsection{Interaction with Other Environments}

The scenario generator and the optimizer are external to the DSS. The DSS provides user-friendly interfaces to interact with these environments.

a) The user can enter data through multiple means. Input layouts can be used to enter the parameters of the model. Also, entire data can be created in spreadsheets and can be imported into the database through the menu driven procedures or by a direct command of the database.

b) The generated LP is written in the standard MPS format. This MPS format is widely accepted by all optimizers, including CPLEX. It is possible to use any other matrix represenation of the problem by having a different matrix generator code.

c) The DSS can also export optimal data in a simple spreadsheet format which can be utilized for further analysis.

\subsection{Report Generation}

The DSS should also have the feature of generating reports as required by the user. It should also have the interface to provide an easy snapshot of the optimal solution. 
The DSS generates the solution summary in simple, easy-to-understand formats as shown in a Grand Summary or a Periodwise Summary. Further information on the optimal solution is easily available in the output layouts of the respective data files.

The optimal solution generated by the optimizer needs to be reported in a coherent manner to the user. In the field of asset-liability management, such a report must contain information about the expected value of the account reserves, the risk factors, etc. Two types of solution summary reporting are available for the user: Grand Summary and Periodwise Summary. The information provided in these two layouts is completely different and is oriented towards the ALM problem. Some brief details of the two types of solution summary reporting are as follows:

Grand Summary: In this summary, the user is provided with a brief snapshot of the return and risk profile of the optimizer output. The value of the expected reserves at the end-of-period represents the 'returns' profile for the asset allocation strategy. The Value at Risk (VaR) and Conditional Value at Risk (CVaR) represent the 'risk' profile of the asset allocation strategy. In finance management, value at risk (VaR) [29] is a widely used risk measure of the risk of loss on a specific portfolio of financial assets. It represents what is the maximum loss that is possible for $1 \%$ or $5 \%$ level. The Conditional value at risk represents the conditional expectation of the financial loss. At $1 \%$ or 5\% [30] 
Figure 6 Asset Time Scenario File: Input Display

\begin{tabular}{|c|c|c|c|}
\hline \multirow{2}{*}{24 of 32} & \multicolumn{3}{|c|}{ Asset Time Scenario } \\
\hline & & Account Name: Share & \\
\hline \begin{tabular}{|l} 
Save \\
\end{tabular} & & Asset Identifier 2 & \\
\hline First Record & & Asset Name Bonds & \\
\hline & & Asset Identifier 1 & \\
\hline \begin{tabular}{|l|} 
Last Record \\
\end{tabular} & & Time Name Year1 & \\
\hline & & Time Identifier 2 & \\
\hline Previous Record & & Scenario Name Sc.ent & \\
\hline Next Record & & Scenario Identifier 4 & \\
\hline & & Transection Cost 0.05 & \\
\hline \begin{tabular}{|l|} 
Cancel \\
\end{tabular} & & & \\
\hline & Buy Min 250 & Hold Min 320 & Sell Min 130 \\
\hline \begin{tabular}{|l|} 
Delete Record \\
\end{tabular} & Buy Max 40000 & Hold Max 65000 & Sell Max 10000 \\
\hline
\end{tabular}

Figure 7 Period wise Summary

\begin{tabular}{|c|c|c|c|}
\hline \multicolumn{4}{|c|}{ Periodwise Summary } \\
\hline Period & & 4 & \\
\hline Expected Overall Reserves & Rs. & 55411.72 & \\
\hline Expected Policyholder reserves & Rs. & 28878.93 & \\
\hline Expected Shareholder reserves & Rs. & 26532.79 & \\
\hline Expected Premium Inflows & Rs. & 5281.91 & \\
\hline Expected Policy Related Outflows & Rs. & 1581.46 & \\
\hline Expected Policyholder Income & Rs. & 4780.09 & \\
\hline Expected Shareholder Income & Rs. & 4380.38 & \\
\hline & & & one \\
\hline
\end{tabular}


Periodwise Summary: This provides a periodwise snapshot of the optimal output. It lists the expected reserve levels at the period of choice, the expected income from investment in the two accounts, the expected premium inflows, and the expected policy related outflows. Figure 6 provides an illustration of this layout.

Figure 8 Grand Summary

\begin{tabular}{||l|c||}
\hline \hline \multicolumn{2}{|c|}{ Grand Summary } \\
\hline Net worth at End-Of-Period Less Discounted Shortfalls & INR 84426.91 \\
\hline \hline Expected Policyholder Reserves at End-Of-Period & INR 38836.48 \\
\hline Expected Shareholder Reserves at End-Of-Period & INR 45688.29 \\
\hline Value-at-Risk at 1\% & INR 48757.53 \\
\hline Value-at-Risk at 5\% & INR 56760.48 \\
\hline Conditional Value-at-Risk at 1\% & INR 46970.7 \\
\hline Conditional Value-at-Risk at 5\% & INR 52296.9 \\
\hline
\end{tabular}

\section{Challenges in developing the DSS}

In this section we provide the answers to question four raised on page 2 and discuss the challenges of database management in a multi-stage, multi-scenario environment. Primarily we face two important challenges. One is addressed through an update mode and another through the implementation of nonanticipativity constraints.

\subsection{Update mode}

This mode provides immense flexibility to the DSS as it reduces the amount of time needed for rerunning the program. Once the data is loaded into the database, there are two key processes for obtaining the optimal solution:

1. The first is the generation of the constraints, variables and coefficients files; and

2. the second is the optimization process in the optimizer. 
The problem at hand deals with more than 150000 variables and more than 150000 constraints. The generation of variables, constraints, and coefficients is a time consuming process, especially while dealing with large scale mathematical models. The Update mode is intended to reduce this time by incorporating small changes directly into the [Variables] and [Constraints] files which reduces the time needed to generate the MPS format of the updated problem. If there is no deletion of records in the key files, any modifications in the data fields can be easily reflected in the [Variables] and [Constraints] file without the need to rerun the procedure for generating the variables and constraints. In the Update mode, a parameter is updated at two locations, firstly at its location in the data management system that has the information about the financial parameters of the model, and secondly at its specific location in the [Constraints] and [Variables] file of the model management system . The difficulty here is in accessing the required data point. However, the use of a relational database makes it easier to locate and modify the data point in the database.

\subsection{Non-anticipativity Constraints}

We now address the fifth question mentioned on page 2. One of the requirements of a stochastic optimization is to be able to make a decision in the current time period based on a wide variety of scenarios possible in the future. The robustness of the solution is dependent on the effective modeling of these scenarios. One of the challenges in generating the constraints in the MPS format is in formulating the non-anticipativity constraints. For the first stage decision variables, all the decision variables must have the same optimal value for them to be implementable, whereas from the second period onwards, for each set of child scenarios succeeding a common parent scenario, the decision variables in the parent period need to have the same optimal values. This requires that we equate all the first stage decision variables. The development of constraints to ensure these conditions are maintained is a challenging task in developing a multi-scenario multi-stage DSS. Thus, a better optimal solution through stochastic optimization is obtained by increasing the complexity of the modeling process. 
One way of implementing a multi-scenario optimization model is to create $n$ independent scenarios and to formulate the model accordingly. Here, all scenarios are completely independent of each other and complicated non-anticipativity constraints need not be used to model the same. But this does not correctly reflect real life conditions. Developing a stochastic linear program for a set of completely independent scenarios is a a challenging task, and the complexity is limited only by the number of scenarios included in the model. The tree representing completely independent scenarios is shown in Figure 9.
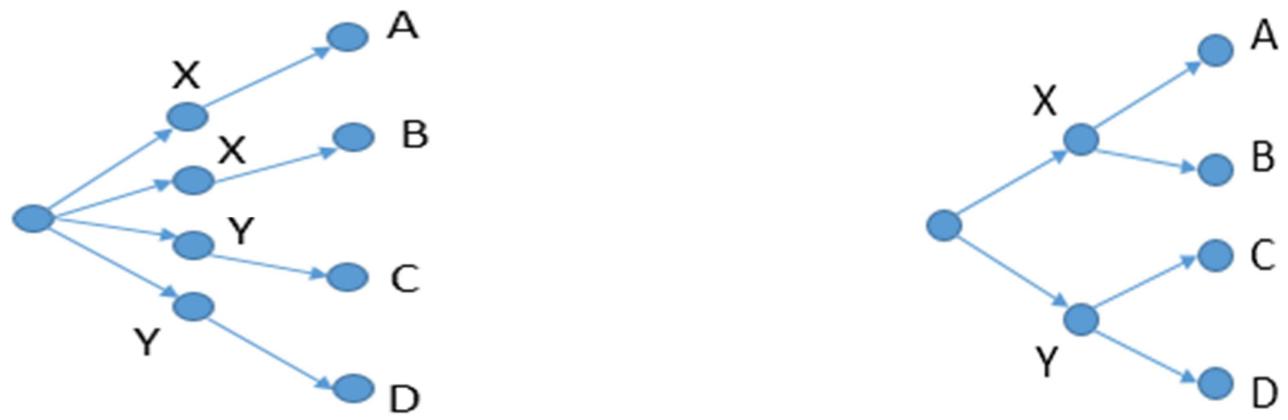

This type of modeling can be modified to even model real life scenario trees. A more realistic scenario tree can be shown (Figure 10). The modeling for the realistic scenario tree, as shown above, can be accomplished by modifying the modeling technique used for independent scenario structures. The key here is to correctly model the parent-child structure. For example, if two scenarios A and B (in time period $n$ ) are the children of the same parent scenario $X$ (in time period $n-1$ ), then the preceding parameters and the variables impacting the two scenarios A and B must be the same. For example, the premium inflows in the time $\mathrm{n}-1$ for both the scenarios must be the same. The parametric part of the problem is taken care of in the scenario generator which ensures that these parameters adhere to the scenario structure. 
So, now the model has two independent scenarios but with the same parameters for the parent scenarios. But even with this restriction, the model is still free to optimize the variables based on the information available about the future in the individual scenarios. Thus, the model could have two different values for the variables in the parent scenario. This is also known as the anticipatory effect in stochastic modeling, where the value of the decision variable in the parent scenario is based not on the entire bouquet of future scenarios but on the individual future scenarios. At each node, we need a unique optimal decision with respect to all future developments. To avoid this, we implement nonanticipativity constraints. In these constraints, the decision variables in the parent scenario for all the successor scenarios are forced to the same value. Thus, for our illustration, for each decision variable in the parent scenario $\mathrm{X}$, we would have one constraint equating the individual decision variables for the preceding scenarios A and B. A full detailed illustration is given in Appendix 1. This is relatively easy in a two stage SLP, but more challenging in a multi stage SLP.

The non-anticipativity constraints thus replicate the scenario structure in the stochastic linear programming formulation. The matrix generator code generates the constraints and variables for any scenario tree defined in the database by the relevant fields. To do this, we first generate constraints for all the respective branches of the scenario tree. Then, we identify the location of each scenario in the scenario tree from the Time-Scenario combination data. Thus, for a set of $p$ successors from a common predecessor, we have $p-1$ non-anticipativity constraints for each decision variable.

\section{Conclusion}

In this study, we introduce a multi-scenario multi-period DSS of asset-liability management for an insurance firm. Though database optimization implementation has been studied extensively for many process industries, we demonstrate the same for an ALM environment. The challenges in developing database management systems to work in a synchronous way with large scale modeling problems are addressed in this research. Also, in terms of mathematical modelling, this is possibly the first attempt at liability side modelling. 
The work can be extended to many areas. This DSS needs to be tested with the real or pseudo real data. In our forthcoming paper [ ] we discuss this and show the impact of Var, and CVar on the variations of parameters value.

We can use simulation in order to test the DSS. Fuzzy linear programing and fuzzy stochastic linear programming are operations research tools for modeling imprecise information about the future. The database system developed for the DSS is capable of working with fuzzy data sets. A similar extension of this work can be done to incorporate stochastic fuzzy linear programming models as well.

Figure 11: A generalized Tree

Figure 12: A More reorganized tree
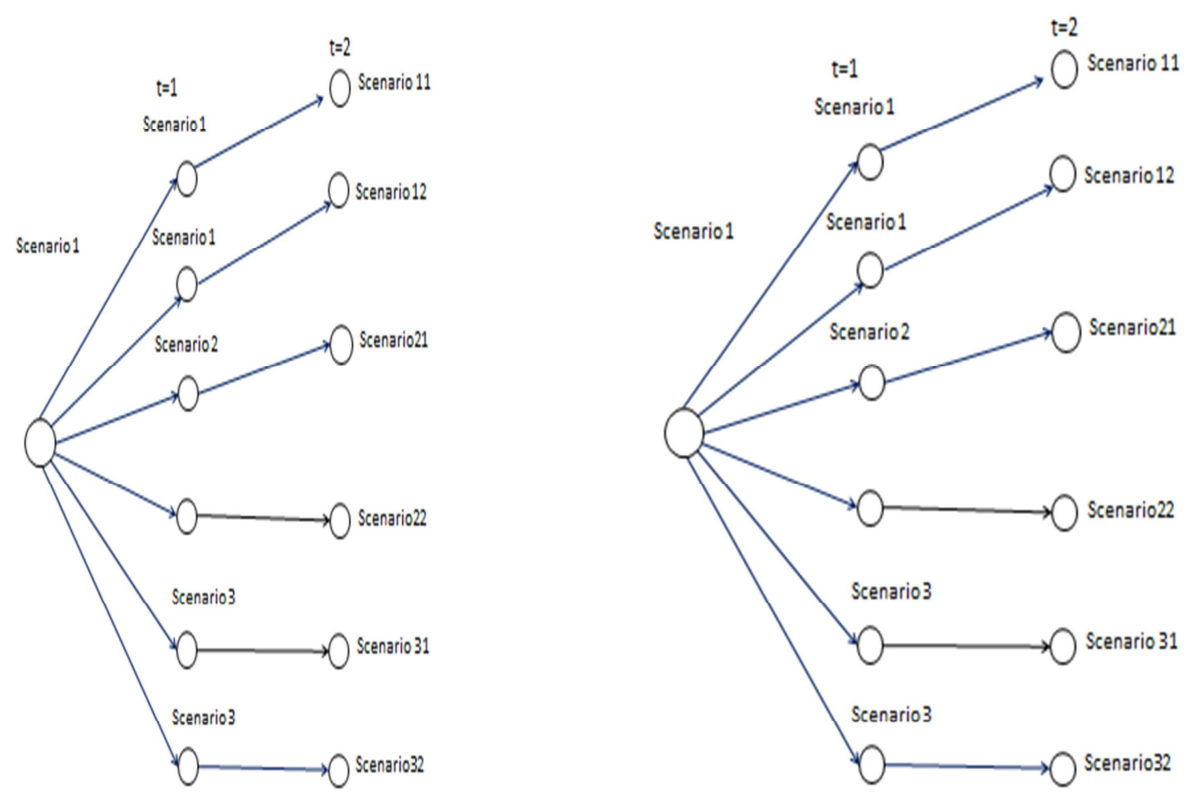


\section{Appendix 1:}

\section{Sets/indices}

$\tau=\{1,2, \ldots \mathrm{T}\}$ is the set of time periods in the planning horizon, indexed by $\mathrm{t}$.

$\mathscr{G}=\{1,2, \ldots \mathrm{I}\}$ is the set of asset classes in the ALM model, indexed by $\mathrm{i}$.

$J=\{1,2, \ldots \mathrm{J}\}$ is the set of liability classes in the ALM model, indexed by $\mathrm{j}$

$S=\{1,2, \ldots \mathrm{S}\}$ is the set of scenarios used in the ALM model,

$\mathrm{A}=\{\mathrm{M}, \mathrm{N}\}$ is the set of accounts in the ALM model. $\mathrm{M}$ is the notation used for the policyholders' account and $\mathrm{N}$ is the notation for the shareholders' account.

\section{Parameters}

$\mathrm{X}_{\mathrm{MOi}} / \mathrm{X}_{\mathrm{NO} 0}=$ Initial fund value invested in asset i from the policyholders' / (shareholders') account, for each $i \in \mathfrak{G}$

$\mathrm{F}_{\mathrm{tj}} / \mathrm{L}_{\mathrm{tj} \mathrm{s}}=$ Premium inflows / Maturity outflows in the time period between $\mathrm{t}-1$ and $\mathrm{t}$ towards liability class $\mathrm{j}$ under scenario $\mathrm{s}$, for each $\mathrm{j} \in \mathbf{J}, \mathrm{s} \in S$ and $\mathrm{t} \in \tau$

$\mathrm{Q}_{\mathrm{tj}} / \mathrm{E}_{\mathrm{t} \mathrm{js}}=$ Death claims / Policy surrender outflows in the time period between $\mathrm{t}-1$ and $\mathrm{t}$ towards liability class $\mathrm{j}$ under scenario $\mathrm{s}$, for each $\mathrm{j} \in \mathbf{J}, \mathrm{s} \in S$ and $\mathrm{t} \in \tau$

$\mathrm{CC}_{\mathrm{t} \mathrm{js}} / \mathrm{CO}_{\mathrm{tjj}}=$ Commission / Operating expenses in the time period $(\mathrm{t}-1, \mathrm{t})$ towards liability class $\mathrm{j}$ under scenario $s$, for each $\mathrm{j} \in \mathbf{J}, \mathrm{s} \in S$ and $\mathrm{t} \in \tau$

$\mathrm{RI}_{\mathrm{tis}} / \mathrm{RP}_{\mathrm{tis}}=$ Income return / Price return on asset class i invested in time period $\mathrm{t}-1$ until time period $\mathrm{t}$ under scenario s, for each $i \in \mathscr{Y}, \mathrm{s} \in S$ and $\mathrm{t} \in \tau$

$\gamma_{\text {tis }}=$ Transaction cost towards buying or selling of an asset $\mathrm{i}$ in the period $\mathrm{t}$ under scenario $\mathrm{s}$, for each $\mathrm{i} \in \mathscr{\Im}, \mathrm{s} \in S$ and $\mathrm{t} \in \tau$

$\beta /(1-\beta)=$ Ratio of surplus sharing with the policyholders' / shareholders' account.

$\mathrm{p}_{\mathrm{ts}}=$ Probability of occurrence of scenario $\mathrm{s}$ in time period $\mathrm{t}$ fors $\in S$ and $\mathrm{t} \in \tau$

$\mathrm{r}=$ Discount rate for the model . 


\section{Variables}

\section{Policyholders' or Shareholders' account}

$X_{\text {Mtis }} / X_{\text {Ntis }}=$ Amount of money invested in asset $\mathrm{i}$ at the beginning of time period $\mathrm{t}$ under scenario $\mathrm{s}$ from the policyholders' account or shareholders account) after buying and selling transactions for the period $\mathrm{t}$ are done, for each $\mathrm{i} \in \mathscr{\Im}, \mathrm{s} \in S$ and $\mathrm{t} \in \tau$

$\mathrm{X}_{\mathrm{Mtis}}^{\text {buy }} / \mathrm{X}_{\mathrm{Mtis}}^{\text {sell }}=$ Amount of asset $\mathrm{i}$ bought $/$ sold at the beginning of time period $\mathrm{t}$ under scenario s from the policyholders' account, for each $\mathrm{i} \in \mathfrak{G}, \mathrm{s} \in S$ and $\mathrm{t} \in \tau$

$\mathrm{X}_{\mathrm{Ntis}}^{\text {buy }} / \mathrm{X}_{\mathrm{Ntis}}^{\text {sell }}=$ Amount of asset $\mathrm{i}$ bought $/$ sold at the beginning of time period $\mathrm{t}$ under scenario $\mathrm{s}$ from the shareholders' account, for each $i \in \mathscr{G}, \mathrm{s} \in S$ and $\mathrm{t} \in \tau$

$v_{\mathrm{ts}}$ - Shortfall of policyholders' income over the commissions and operating expenses which is to be funded by the shareholders' account, for each $s \in S$ and $t \in \tau$

$v_{\text {ts }}$ - Surplus of policyholders' income over the commissions and operating expenses which would be shared in the ratio $\beta$ and $1-\beta$ between the policyholders' and the shareholders' account, for each $\mathrm{s} \in S$ and $\mathrm{t} \in \tau$

\section{Derived Variables}

$\mathrm{X}_{\mathrm{M} 0} / \mathrm{X}_{\mathrm{N} 0}=$ Initial liabilities accumulated in the policyholders' / shareholders' reserve

$\mathrm{D}_{\mathrm{ts}} / \mathrm{H}_{\mathrm{ts}}=$ Total income earned in the policyholders' / shareholders' account in the period $\mathrm{t}$ under scenario $\mathrm{s}$, for each $\mathrm{s} \in S$ and $\mathrm{t} \in \tau$

$\mathrm{T}_{\mathrm{Mtis}} / \mathrm{T}_{\mathrm{Ntis}}=$ Total transaction costs incurred on transactions in the policyholders' / shareholders' account of asset $\mathrm{i}$ in time period $\mathrm{t}$ under scenario s, for each $\mathrm{i} \in \mathscr{I}, \mathrm{s} \in S$ and $\mathrm{t} \in \tau$

$\mathrm{TPO}_{\mathrm{ts}}=$ Total policy related outflows in the time period between $\mathrm{t}-1$ and $\mathrm{t}$ under scenario $\mathrm{s}$, for each $\mathrm{s}$ $\in S$ and $t \in \tau$

$\mathrm{F}_{\mathrm{ts}}=$ Total premium inflows in the time period between $\mathrm{t}-1$ and $\mathrm{t}$ under scenario $\mathrm{s}$, for each $\mathrm{s} \in S$ and $\mathrm{t} \in$ $\tau$

$\mathrm{CC}_{\mathrm{ts}}=$ Total commissioning expenses in the time period between $\mathrm{t}-1$ and $\mathrm{t}$ under scenario $\mathrm{s}$, for each $\mathrm{s}$ $\in S$ and $t \in \tau$ 
$\mathrm{M}_{\mathrm{ts}} / \mathrm{N}_{\mathrm{ts}}=$ Accumulated reserves in the policyholders' / shareholders'account at the end of time period $\mathrm{t}$ under scenario $\mathrm{s}$, for each $\mathrm{s} \in S$ and $\mathrm{t} \in \tau$

\section{Bounds}

$\mathrm{L}_{\mathrm{Mtis}}^{\text {buy }} / \mathrm{L}_{\mathrm{Mtis}}^{\text {sell }}=$ Lower bound on the amount of money worth of asset $\mathrm{i}$ that can be bought / sold at the beginning of the period t under scenario s from policyholders' account, for each $\mathrm{i} \in \mathscr{G}, \mathrm{s} \in S$ and $\mathrm{t} \in \tau$ $\mathrm{L}_{\mathrm{Mtis}} / U_{M t i s}=$ Lower / Upper bound on the amount of money that can be invested in asset $\mathrm{i}$ at the beginning of period t under scenario s from policyholders' account, for each $\mathrm{i} \in \mathfrak{G}, \mathrm{s} \in S$ and $\mathrm{t} \in \tau$ $\mathrm{U}_{\mathrm{Mtis}}^{\text {buy }} / \mathrm{U}_{\mathrm{Mtis}}^{\text {sell }}=$ Upper bound on the amount of money worth of asset $\mathrm{i}$ that can be bought / sold at the beginning of the period t under scenario s from policyholders' account, for each $i \in \mathscr{I}, \mathrm{s} \in S$ and $t \in \tau$ $\mathrm{U}_{\mathrm{Ntis}} / \mathrm{L}_{\mathrm{Ntis}}=\mathrm{Lower} / \mathrm{Upper}$ bound on the amount of money that can be invested in asset $\mathrm{i}$ at the beginning of period t under scenario s from shareholders' account, for each $\mathrm{i} \in \mathscr{G}, \mathrm{s} \in S$ and $\mathrm{t} \in \tau$

$\mathrm{L}_{\mathrm{Ntis}}^{\text {buy }} / \mathrm{L}_{\mathrm{Ntis}}^{\text {sell }}=$ Lower bound on the amount of money worth of asset $\mathrm{i}$ that can be bought / sold at the beginning of the period $t$ under scenario s from shareholders' account, for each $i \in \mathscr{G}, \mathrm{s} \in S$ and $\mathrm{t} \in \tau$ $\mathrm{U}_{\mathrm{Ntis}}^{\text {buy }} / \mathrm{U}_{\mathrm{Ntis}}^{\text {sell }}=$ Upper bound on the amount of money worth of asset $\mathrm{i}$ that can be bought / sold at the beginning of the period $\mathrm{t}$ under scenario s from shareholders' account, for each $\mathrm{i} \in \mathscr{G}, \mathrm{s} \in S$ and $\mathrm{t} \in \tau$

Constraints: A node in the scenario tree is defined by the period ' $t$ ' and the scenario ' $s$ ', $p_{t s}$ as the probability of the scenario $\mathrm{s}$ for a given period $\mathrm{t}$, such that

$$
\sum_{\mathrm{s}} \mathrm{p}_{\mathrm{ts}}=1 \quad \text { For all } \mathrm{t} \in \tau
$$

\section{$\underline{\text { Initial Reserve Constraints }}$}

The initial reserves in each of the accounts is the sum of all the initial investments in various asset classes in the respective account. We define these constraints for the initial reserve variables for each of the two accounts.

$$
\mathrm{X}_{\mathrm{M} 0}=\sum_{\mathrm{i}} \mathrm{X}_{\mathrm{M} 0 \mathrm{i}} \quad \mathrm{s} \in S
$$




$$
\mathrm{X}_{\mathrm{N} 0}=\sum_{\mathrm{i}} \mathrm{X}_{\mathrm{N} 0 \mathrm{i}} \quad \mathrm{s} \in S
$$

\section{Investment Reserve Constraints}

The reserves at the end of the time period $t$ are invested in various assets. For the first period, the initial reserves are invested in the various asset classes at the beginning of the period. In the later periods, investment at the beginning of any period $t$ is made from the accumulated investment reserves at the end of the previous period $(t-1)$. Limitations of investments would be individually modeled by having separate constraints.

$$
\begin{array}{rr}
\mathrm{X}_{\mathrm{M} 0}=\sum_{\mathrm{i}} \mathrm{X}_{\mathrm{M} 1 \mathrm{is}} & \mathrm{s} \in S \\
\mathrm{X}_{\mathrm{N} 0}=\sum_{\mathrm{i}} \mathrm{X}_{\mathrm{N} 1 \mathrm{is}} & \mathrm{s} \in S \\
\mathrm{M}_{\mathrm{ts}}=\sum_{\mathrm{i}} \mathrm{X}_{\mathrm{M}(\mathrm{t}+1) \text { is }} & \mathrm{t} \in\{1, \ldots, \mathrm{T}-1\}, \mathrm{s} \in S \\
\mathrm{~N}_{\mathrm{ts}}=\sum_{\mathrm{i}} \mathrm{X}_{N(\mathrm{t}+1) \text { is }} & \mathrm{t} \in\{1, \ldots, \mathrm{T}-1\}, \mathrm{s} \in S
\end{array}
$$

\section{Income Constraints:}

Returns are generated from investments made in the asset classes. This income is reduced because of the transaction costs incurred in restructuring the asset portfolio. By restructuring the asset portfolio, we imply the buying and selling among the asset classes based on the additional inflows less outflows and the expectation of the future uncertainties. Income is generated from investments made from both policyholders' account as well as the shareholders' account.

The income earned by the investments from the policyholders' account is $\mathrm{D}_{\mathrm{ts}}$ and is given by

$$
\mathrm{D}_{\mathrm{ts}}=\sum_{\mathrm{i}}\left\{\left(\mathrm{RI}_{\mathrm{tis}}+\mathrm{RP}_{\mathrm{tis}}\right) \mathrm{X}_{\mathrm{Mtis}}-\mathrm{T}_{\mathrm{Mtis}}\right\} \quad \mathrm{t} \in \tau, \mathrm{s} \in S
$$

The first term in the summation indicates the returns generated from the investments in the respective asset classes. The second term in the summation denotes the transaction costs incurred in the particular asset class. The transaction costs are modeled in equation A10 based on the asset balance constraints in A12.

The income earned by the investments from the shareholders' account is $\mathrm{H}_{\mathrm{ts}}$ and is given by 


$$
\mathrm{H}_{\mathrm{ts}}=\sum_{\mathrm{i}}\left\{\left(\mathrm{RI}_{\mathrm{tis}}+\mathrm{RP}_{\mathrm{tis}}\right) \mathrm{X}_{\mathrm{Ntis}}-\mathrm{T}_{\mathrm{Ntis}}\right\} \quad \mathrm{t} \in \tau, \mathrm{s} \in S
$$

\section{$\underline{\text { Transaction Cost Constraints: }}$}

Transaction costs are incurred when the asset portfolio is restructured by buying or selling of assets. Each of these transactions incurs a cost. Buying or selling in any asset class is charged a certain fee. This fee is generally based on the value of these transactions (amount of asset worth bought or sold).

Transaction cost for investments from the policyholders' account in the asset class $\mathrm{i}$ for the period $\mathrm{t}$ under scenario $\mathrm{s}$ is given by $\mathrm{T}_{\mathrm{Mtis}}$ and is calculated as

$$
\mathrm{T}_{\text {Mtis }}=\gamma_{\text {tis }}\left(\mathrm{X}_{\text {Mtis }}^{\text {buy }}+\mathrm{X}_{\text {Mtis }}^{\text {sell }}\right) \quad \mathrm{i} \in \mathfrak{g}, \mathrm{t} \in \tau, \mathrm{s} \in S
$$

Transaction cost for investments from the shareholders' account in the asset class $\mathrm{i}$ for the period $\mathrm{t}$ under scenario $\mathrm{s}$ is given by $\mathrm{T}_{\mathrm{Ntis}}$ and is calculated as

$$
\mathrm{T}_{\mathrm{Ntis}}=\gamma_{\mathrm{tis}}\left(\mathrm{X}_{\mathrm{Ntis}}^{\text {buy }}+\mathrm{X}_{\mathrm{Ntis}}^{\text {sell }}\right) \quad \mathrm{i} \in \mathscr{G}, \mathrm{t} \in \tau, \mathrm{s} \in S
$$

\section{Asset Balance Constraints:}

The asset portfolio is reorganized by buying or selling of assets over periods. As the firm receives fresh inflows, it restructures its asset holding portfolio by buying fresh investments into the asset classes. These investments are also reorganized based on the expectation of future uncertainties. This balance of asset holdings over periods is modeled by utilization of the asset balance constraints.

For the policyholders' account, $\mathrm{X}_{\mathrm{Mtis}}^{\text {buy }}$ and $\mathrm{X}_{\mathrm{Mtis}}^{\text {sell }}$ are modeled as

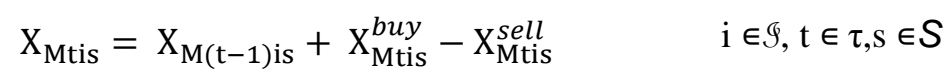

For the shareholders' account, $\mathrm{X}_{\mathrm{N} \text { tis }}^{\text {buy }}$ and $\mathrm{X}_{\mathrm{Ntis}}^{\text {sell }}$ are modeled as

$$
\mathrm{X}_{\mathrm{Ntis}}=\mathrm{X}_{\mathrm{N}(\mathrm{t}-1) \mathrm{is}}+\mathrm{X}_{\mathrm{Ntis}}^{\text {buy }}-\mathrm{X}_{\mathrm{Ntis}}^{\text {sell }} \quad \mathrm{i} \in \mathscr{G}, \mathrm{t} \in \tau, \mathrm{s} \in S
$$

\section{Upper and Lower bound constraints for Investments (Policy holders' Account):}

The investment in any asset class must be within the lower and upper bounds for the asset class.

These bounds are expressed for the policyholders' account as 


$$
\begin{aligned}
& \mathrm{L}_{\mathrm{Mtis}} \leq \mathrm{X}_{\mathrm{Mtis}} \leq \mathrm{U}_{\mathrm{Mtis}} \mathrm{i} \in \mathscr{G}, \mathrm{t} \in \tau, \mathrm{s} \in S(\mathrm{~A} 14) \\
& \mathrm{L}_{\mathrm{Mtis}}^{\text {buy }} \leq \mathrm{X}_{\text {Mtis }}^{\text {buy }} \leq \mathrm{U}_{\text {Mtis }}^{\text {buy }} \mathrm{i} \in \mathscr{G}, \mathrm{t} \in \tau, \mathrm{s} \in S(\mathrm{~A} 15) \\
& \mathrm{L}_{\mathrm{Mtis}}^{\text {sell }} \leq \mathrm{X}_{\text {Mtis }}^{\text {sell }} \leq \mathrm{U}_{\text {Mtis }}^{\text {sell }} \mathrm{i} \in \mathscr{G}, \mathrm{t} \in \tau, \mathrm{s} \in S(\mathrm{~A} 16) \\
& \mathrm{L}_{\mathrm{Ntis}} \leq \mathrm{X}_{\mathrm{Ntis}} \leq \mathrm{U}_{\mathrm{Ntis}} \mathrm{i} \in \mathscr{G}, \mathrm{t} \in \tau, \mathrm{s} \in S(\mathrm{~A} 17) \\
& \mathrm{L}_{\mathrm{Ntis}}^{\text {buy }} \leq \mathrm{X}_{\mathrm{Ntis}}^{\text {buy }} \leq \mathrm{U}_{\mathrm{Ntis}}^{\text {buy }} \mathrm{i} \in \mathscr{G}, \mathrm{t} \in \tau, \mathrm{s} \in S(\mathrm{~A} 18) \\
& \mathrm{L}_{\mathrm{Ntis}}^{\text {sel }} \leq \mathrm{X}_{\mathrm{Ntis}}^{\text {sell }} \leq \mathrm{U}_{\mathrm{Ntis}}^{\text {sell }} \mathrm{i} \in \mathscr{G}, \mathrm{t} \in \tau, \mathrm{s} \in S(\mathrm{~A} 19)
\end{aligned}
$$

\section{Total Commissioning Expenses Constraint:}

The total commissioning expenses is the summation of the commissioning expenses incurred over all liabilities for a given time-scenario combination

$$
\mathrm{CC}_{\mathrm{ts}}=\sum_{\mathrm{j}} \mathrm{CC}_{\mathrm{tjs}}
$$$$
\mathrm{t} \in \tau, \mathrm{s} \in S
$$

\section{Total Premium Inflows Constraint:}

The total premium inflows in a given time-scenario combination is the summation of the premium inflows obtained over all liabilities for the given time-scenario combination

$$
\mathrm{F}_{\mathrm{ts}}=\sum_{\mathrm{j}} \mathrm{F}_{\mathrm{tjs}} \quad \mathrm{t} \in \tau, \mathrm{s} \in S
$$

\section{Total Policy Related Outflows Constraint:}

$\mathrm{TPO}_{\mathrm{ts}}$ is the total policy related outflows which is the summation of maturity outflows, death claims and surrender outflows and is given by

$$
\mathrm{TPO}_{\mathrm{ts}}=\sum_{\mathrm{j}}\left(\mathrm{L}_{\mathrm{tjs}}+\mathrm{Q}_{\mathrm{tjs}}+\mathrm{E}_{\mathrm{tjs}}\right) \quad \mathrm{t} \in \tau, \mathrm{s} \in S
$$

\section{Surplus-Deficit Constraints:}

The income earned by the investments from the policyholders' account should offset the commissions and other operating expenses. The RHS of constraint A23 represents these expenses. The first term of 
the LHS represents the income earned in the policyholders' account. $v_{\mathrm{ts}}$ and $v_{\mathrm{ts}}$ are deficient and surplus variables respectively. These are used to balance the above inequality.

If the income is less than the expenses, then the deficit is funded by the shareholders' account. If there is a surplus, the surplus is divided between the shareholder's account and the policyholders' account in the pre-determined ratio $(\beta)$.

$$
\mathrm{D}_{\mathrm{ts}}+\mathrm{v}_{\mathrm{ts}}-v_{\mathrm{ts}}=\mathrm{CO}_{\mathrm{ts}}+\mathrm{CC}_{\mathrm{ts}} \quad \mathrm{t} \in \tau, \mathrm{s} \in S
$$

\section{End-of-Period Reserves (Policy holders' Account):}

In case of a deficiency, $v_{\mathrm{ts}}$ would be funded by the shareholders' account. In case of a surplus, $v_{\mathrm{ts}}$ would be shared in the proportion of $\beta$ and $1-\beta$ between the shareholders' account and the policyholders' account.

Hence, the total policy holder reserve at the end of the period t would be

$$
\mathrm{M}_{\mathrm{ts}}=\mathrm{M}_{(\mathrm{t}-1) \mathrm{s}}+\mathrm{F}_{\mathrm{ts}}-\mathrm{TPO}_{\mathrm{ts}}+\beta v_{\mathrm{ts}} \quad \mathrm{t} \in \tau, \mathrm{s} \in S
$$

Maturity outflows would include the bonus payout to the maturing policies and would be developed from the aggregated scenario generation module. The commission expenses are also liability class (policy product) dependent; but as they are to be offset against income generation they are not included in the policy related outflows.

\section{Deficit Make-up Constraints:}

As the shareholders' account is the buffer for any deficit in the policyholders' account, the value of this reserve prior to any surplus transfer should be greater than the possible deficit.

$$
\mathrm{N}_{(\mathrm{t}-1) \mathrm{s}}+\mathrm{H}_{\mathrm{ts}} \geq \mathrm{v}_{\mathrm{ts}} \quad \mathrm{t} \in \tau, \mathrm{s} \in S
$$

\section{End-of-Period Reserves (Share holders' Account):}

Thus, the shareholders' reserve at the end of the period t would take into account any surplus or deficit transfers to the policy holders' account as well as the income generated by its own investments.

$$
\mathrm{N}_{\mathrm{ts}}=\mathrm{N}_{(\mathrm{t}-1) \mathrm{s}}+\mathrm{H}_{\mathrm{ts}}+(1-\beta) v_{\mathrm{ts}}-\mathrm{v}_{\mathrm{ts}} \quad \mathrm{t} \in \tau, \mathrm{s} \in S
$$




\section{$\underline{\text { Non-anticipativity constraints }}$}

The decision variables $\mathrm{X}_{\mathrm{Mtis}}, \mathrm{X}_{\mathrm{Mtis}}^{\text {buy }}, \mathrm{X}_{\mathrm{Mtis}}^{\text {sell }}, \mathrm{X}_{\mathrm{Ntis}}, \mathrm{X}_{\mathrm{Ntis}}^{\text {buy }}, \mathrm{X}_{\mathrm{Ntis}}^{\text {sell }}$ would be constrained over the succeeding scenarios to ensure that the succeeding scenarios from the same parent scenario have the same decision variables as inputs.

A general scenario tree is provided in Figure 10

The variables in the scenarios 11 and $12(\mathrm{t}=2)$, emanating from the common preceding scenario 1 , would be represented as

$\mathrm{X}_{\mathrm{N} 2 \mathrm{i} 1}, \mathrm{X}_{\mathrm{N} 2 \mathrm{i} 1}^{\text {buy }}, \mathrm{X}_{\mathrm{N} 2 \mathrm{i} 1}^{\text {sel }}, \mathrm{X}_{\mathrm{M} 2 \mathrm{i} 1}, \mathrm{X}_{\mathrm{M} 2 \mathrm{i} 1}^{\text {buy }}, \mathrm{X}_{\mathrm{M} 2 \mathrm{i} 1}^{\text {sell }}$, for scenario 11 (denoted as 1) and

$\mathrm{X}_{\mathrm{N} 2 \mathrm{i} 2}, \mathrm{X}_{\mathrm{N} 2 \mathrm{i} 2}^{\text {buy }}, \mathrm{X}_{\mathrm{N} 2 \mathrm{i} 2}^{\text {sell }}, \mathrm{X}_{\mathrm{M} 2 \mathrm{i} 2}, \mathrm{X}_{\mathrm{M} 2 \mathrm{i} 2}^{\text {buy }}, \mathrm{X}_{\mathrm{M} 2 \mathrm{i} 2}^{\text {sell }}$ for scenario 12 (denoted as 2)

For scenario 1, the same variables would be represented differently for the two tree branches $(t=1)$

$\mathrm{X}_{\mathrm{N} 1 \mathrm{i} 1}, \mathrm{X}_{\mathrm{N} 1 \mathrm{i} 1}^{\text {buy }}, \mathrm{X}_{\mathrm{N} 1 \mathrm{i} 1}^{\text {sell }}, \mathrm{X}_{\mathrm{M} 1 \mathrm{i} 1}, \mathrm{X}_{\mathrm{M} 1 \mathrm{i} 1}^{\text {buy }}, \mathrm{X}_{\mathrm{M} 1 \mathrm{i} 1}^{\text {sell }}$, for scenario 11 and

$\mathrm{X}_{\mathrm{N} 1 \mathrm{i} 2}, \mathrm{X}_{\mathrm{N} 1 \mathrm{i} 2}^{\text {buy }}, \mathrm{X}_{\mathrm{N} 1 \mathrm{i} 2}^{\text {sel }}, \mathrm{X}_{\mathrm{M} 1 \mathrm{i} 2}, \mathrm{X}_{\mathrm{M} 1 \mathrm{i} 2}^{\text {buy }}, \mathrm{X}_{\mathrm{M} 1 \mathrm{i} 2}^{\text {sell }}$, for scenario 12

But these two correspond to the same set of variables. Hence, the non - anticipativity constraints for this particular example would be as follows

$$
\begin{aligned}
& \mathrm{X}_{\mathrm{N} 1 \mathrm{i} 1}=\mathrm{X}_{\mathrm{N} 1 \mathrm{i} 2} \mathrm{i} \in \mathfrak{g}, \mathrm{t} \in \tau, \mathrm{s} \in S(\mathrm{~A} 27) \\
& \mathrm{X}_{\mathrm{M} 1 \mathrm{i} 1}=\mathrm{X}_{{\mathrm{M} 1 \mathrm{i} 2^{-}}^{-}} \quad \mathrm{i} \in \mathscr{G}, \mathrm{t} \in \tau, \mathrm{s} \in S(\mathrm{~A} 28) \\
& \mathrm{X}_{\mathrm{N} 1 \mathrm{i} 1}^{\text {buy }}=\mathrm{X}_{{\mathrm{N} 1 \mathrm{i} 2^{-}}^{-}}^{\text {buy }} \quad \mathrm{i} \in \mathscr{G}, \mathrm{t} \in \tau, \mathrm{s} \in S(\mathrm{~A} 29) \\
& \mathrm{X}_{\mathrm{M} 1 \mathrm{i} 1}^{\text {buy }}=\mathrm{X}_{\mathrm{M}_{112^{-}}}^{\text {buy }} \quad \mathrm{i} \in \mathfrak{G}, \mathrm{t} \in \tau, \mathrm{s} \in S(\mathrm{~A} 30) \\
& \mathrm{X}_{\mathrm{N} 1 \mathrm{i} 1}^{\text {sell }}=\mathrm{X}_{\mathrm{N} 1 \mathrm{i} 2^{-}}^{\text {sell }} \quad \mathrm{i} \in \mathscr{G}, \mathrm{t} \in \tau, \mathrm{s} \in S(\mathrm{~A} 31) \\
& \mathrm{X}_{\mathrm{M} 1 \mathrm{i} 1}^{\text {sell }}=\mathrm{X}_{\mathrm{M} 1 \mathrm{i} 2}^{\text {sell }} \mathrm{i} \in \mathscr{G}, \mathrm{t} \in \tau, \mathrm{s} \in S(\mathrm{~A} 32)
\end{aligned}
$$




\section{Objective function}

The objective function for the linear programming model would be to maximize the expected value of the total reserve (policyholders' reserve plus the shareholders' reserve) at the end of the timeframe $\mathrm{T}$ in addition to minimizing the expected discounted value of the deficits encountered (if any) in between. The first summation term denotes the expected end-of-period overall reserve value. The second summation term denotes the discounted value of the shortfalls encountered in the stochastic model.

\section{Maximize}

$$
\sum_{\mathrm{s}} \mathrm{p}_{\mathrm{Ts}}\left(\mathrm{M}_{\mathrm{Ts}}+\mathrm{N}_{\mathrm{Ts}}\right)-\sum_{\mathrm{T}} \sum_{\mathrm{s}} \mathrm{p}_{\mathrm{Ts}} \mathrm{v}_{\mathrm{ts}}(1+\mathrm{r})^{\mathrm{T}-\mathrm{t}}
$$

The non-negativity constraints apply to all the decision variables. 


\section{References}

1. D. Adams and D. Beckett (1999). Programming in 4th Dimension, the Ultimate Guide. Automated Solutions Group: Huntingto Beach, CA, USA.

2. J. R. Birge (1997). State-of-the-art-survey-stochastic programming: Computation andapplications. Informs Journal on Computing, 9(2), 111-133.

3. D. R. Cariño, T. Kent,D. H. Myers, C. Stacy, M. Sylvanus, A.L. Turner, K. Watanabeand W. T. Ziemba (1994). "The Russel-Yasuda Kasai model: An asset-liability model for a Japanese insurance company using multistage stochastic programming." Interfaces 24(1): 29-49.

4. D. R. Carino, D. H. Myers and W. T. Ziemba, (1998). Concepts, Technical Issues, and Uses of the Russell-Yasuda Kasai Financial Planning Model.Operations Research; Vol. 46 (4); pp. $450-462$.

5. V. Dhar and R. Stein, (1997). Intellligent Decision Support Methods. The Science of Knowledge. Upper Saddll River, New Jersey, Prentice - Hall

6. D. R. Dolk, (1986). Data as models: An approach to implementing model management. DecisionSupport Systems, 2(1), 73-80.

7. G. Dutta, (1996). An Optimization-based Decision Support System for Strategic Planning in Process Industries, Doctoral Dissertation, Northwestern University.

8. G. Dutta and R. Fourer, (2004). An Optimization-based Decision Support System for Strategic and Operational Planning in Process Industries, Optimization and Engineering, 5.

9. G. Dutta and R. Fourer, (2008). Database structure for a class of multi-period mathematical programming models. Decision Support Systems, 45(4), 870-883.

10. G. Dutta, R. Fourer, A. Majumdar and D.Dutta, (2007). An Optimization Based Decision Support System for Strategic and Operational Planning within Process Industries: Case of Pharmaceuticals Industry in India, International Journal of Production Economics, 102.

11. G. Dutta, N. Gupta, and R. Fourer, (2011). An Optimization-based Decision Support System for Strategic Planning in a Process Industry: The Case of Aluminium Company in India, The Journal of Operational Research Society, 62.

12. Fayyad (1995). Advances in Knowledge \& Data Mining, AAAII, MIT Press

13. R. Fourer, (1997). Database structures for mathematical programming models. Decision Support Systems, 20(4), 317-344.

14. R. Fourer, D. M. Gay and B. W. Kernighan, (1990). A modeling language for mathematical programming. Management Science, 36(5), 519-554. 
15. A. M. Geoffrion, (1989a). The formal aspects of structured modeling. Operations Research, $37(1), 30-51.166$

16. A. M. Geoffrion, (1989b). Computer-based modeling environments. European Journal of Operational Research, 41(1), 33-43.

17. A. M. Geoffrion, (1991). FW / SM: A Prototype Structured Modeling Environment. Management Science, 37(12), 1513 - 1538.

18. N. Gupta, G. Dutta and R. Fourer (2014) An expanded database structure for a class of multiperiod, stochastic mathematical programming for process industries, Accepted for publication in Decision Support Systems (2014), http://dx.doi.org/10.1016/j.dss.2014.04.003

19. C. W. Holsapple and A. B. Whinston, (1996). Decision Support Systems: A Knowledge-Based Approach, St. Paul, MN: West Publishing

20. M. I. Kusy and W. T. Ziemba, (1986). A bank asset and liability management model. Operations Research; Vol. 34 (3), pp. 356 - 376.

21. H. Markowitz, (1952). Portfolio Selection. The Journal of Finance, 7(1), pp. 77-91.

22. H. Markowitz, (1959). Portfolio Selection: Efficient Diversification of Investments (p. 368). Yale University Press.

23. J. M. Mulvey and W. T. Ziemba, (1998). World Wide Asset Liability Modeling. Edited Volume, Cambridge University Press.

24. G. Mitra, (1982). UIMP: User Interface for Mathematical Programming, ACM Transactions on Mathematical Software, 8(3).

25. S. Sen and J. L. Higle, (1999). An introductory tutorial on stochastic linear programming models. Interfaces, 29(2), $33-61$.

26. R. Sprague and H. Watson, (1993). Decision Support Systems, Putting Theory into Practice. New Jersey: Prentice Hall International.

27. E. Turban and J. E. Aronson, (2004). Decision Support Systems and Intelligent Systems, Prentice Hall, New Jersey.

28. C. Valente, G. Mitra, M. Sadki, M. R. and R. Fourer, (2009), Extending algebraic modelling languages for stochastic programming, INFORMS Journal on Computing 21 (1) : 107- 122

29. http://en.wikipedia.org/wiki/Value at risk (retrieved on May 16, 2014).

30. http://en.wikipedia.org/wiki/Conditional value-at-risk (retrieved on May 16, 2014) 